\title{
Identification of c-Yes expression in the nuclei of hepatocellular carcinoma cells: Involvement in the early stages of hepatocarcinogenesis
}

\author{
TAKAKO NONOMURA ${ }^{1}$, TSUTOMU MASAKI ${ }^{1}$, ASAHIRO MORISHITA ${ }^{1}$, GONG JIAN $^{1}$, \\ NAOHITO UCHIDA ${ }^{1}$, TAKASHI HIMOTO ${ }^{1}$, KUNIHIKO IZUISHI ${ }^{2}$, HISAKAZU IWAMA ${ }^{3}$, \\ HITOSHI YOSHIJI $^{4}$, SEISHIRO WATANABE ${ }^{1}$, KAZUTAKA KUROKOHCHI ${ }^{1}$ and SHIGEKI KURIYAMA ${ }^{1}$ \\ ${ }^{1}$ Department of Gastroenterology and Neurology, ${ }^{2}$ Department of Gastroenterological Surgery, and ${ }^{3}$ Information \\ Technology Center, Kagawa University School of Medicine, 1750-1 Ikenobe, Miki-cho, Kita-gun, Kagawa 761-0793; \\ ${ }^{4}$ Third Department of Internal Medicine, Nara Medical University, 840 Shijo-cho, Kashihara, Nara 634-8522, Japan
}

Received August 4, 2006; Accepted September 29, 2006

\begin{abstract}
It is thought that the subcellular distribution of Src-family tyrosine kinases, including c-Yes binding to the cellular membrane, is membranous and/or cytoplasmic. c-Yes protein tyrosine kinase is known to be related to malignant transformation. However, the expression patterns of c-Yes in hepatocellular carcinoma (HCC) remains unknown. In the present study, we report that c-Yes is expressed not only in the membrane and cytoplasm, but also in the nuclei of cancer cells in some human HCC tissues and in a human HCC cell line. We examined the expression and localization of c-Yes in human HCC cell lines (HLE, HLF, PLC/PRF/5 and Hep 3B) by Western blotting and immunohistochemical analyses; we also examined the expression of c-Yes by immunohistochemistry and Western blotting in the tissues of various liver diseases, including 39 samples from HCC patients. We used an antibody array to detect proteins that bind to nuclear c-Yes in PLC/PRF/5 cell line. c-Yes was found to be expressed in the membranes and cytoplasm of HLE, HLF and Hep 3B HCC cells; it was also detected in the nuclei in addition to the membranes and cytoplasm of PLC/PRF/5 HCC cells. HCC with nuclear c-Yes was detected in 5 of 39 cases (13.0\%), and nuclear c-Yes expression was not detected in normal, chronic hepatitis or cirrhotic livers. All HCCs with nuclear c-Yes expression were well-differentiated, small tumors at the early stages. In the PLC/PRF/5 cell line, the nuclear localization of $\mathrm{c}$-Yes with cyclin-dependent kinase 1
\end{abstract}

Correspondence to: Dr Tsutomu Masaki, Department of Gastroenterology and Neurology, Kagawa University School of Medicine, 1750-1 Ikenobe, Miki-cho, Kita-gun, Kagawa 761-0793, Japan E-mail: tmasaki@med.kagawa-u.ac.jp

Key words: hepatocellular carcinoma, tyrosine kinase, c-Yes, oncogene, cyclin-dependent kinase 1 was confirmed by a protein antibody array. In conclusion, nuclear c-Yes expression was found in cancer cells at the early stages of hepatocarcinogenesis, suggesting that nucleuslocated c-Yes may be a useful marker to detect early-stage HCC.

\section{Introduction}

A large number of cellular protein tyrosine kinase (PTK) genes have been cloned and sequenced. They may be classified into two major groups: growth factor receptor PTKs, and retroviral PTKs or their cellular homologues (1). The primary representatives of the latter are non-receptor-linked and membraneassociated (2). There are at least 9 known Src-related tyrosine kinases: c-Src, c-Yes, c-Lck, c-Fyn, c-Hck, c-Lyn, c-Blk, c-Fgr and c-Yrk proto-oncogene products (3). The cellular oncogene c-Yes, a member of the Src family, encodes a $62-\mathrm{kDa}$, cytoplasmic and membrane-associated PTK (4). c-Yes expression and its kinase activity are known to increase in colorectal cancer $(5,6)$, melanoma $(7,8)$, hepatocellular carcinoma (HCC) (9) and metastatic liver cancer (10).

It is thought that Src-family tyrosine kinases including c-Yes bind to the cellular membrane; their subcellular distribution is membranous and/or cytoplasmic. However, we report here that c-Yes is expressed not only in the membrane and cytoplasm, but also in the nuclei of cancer cells in a subset of HCC cells. In addition, nuclear colocalization of c-Yes with cyclin-dependent kinase 1 (Cdk1) was confirmed by a protein antibody array. To the best of our knowledge, this report is the first study demonstrating that the expression of c-Yes was detected in the nuclei of HCC cells. Furthermore, all HCCs with nuclear c-Yes expression were well-differentiated, small tumors at the early stages.

\section{Materials and methods}

Tissue samples. Tissue samples were obtained by surgical resection or liver biopsy from 39 patients with HCC (31 males, 8 females; mean age, $65.6 \pm 11.9$ years; range, 31-89 
Table I. Clinical parameters of HCC patients with and without nuclear c-Yes expression.

\begin{tabular}{|c|c|c|c|c|}
\hline & & $n$ of c-Yes in $n$ & & \\
\hline & $(-)$ & $(+)$ & Total & Test \\
\hline & 34 & 5 & 39 & \\
\hline Age (years) & & & & \\
\hline Mean $\pm \mathrm{SD}$ & $65.9 \pm 11.7$ & $63.2 \pm 14.1$ & $65.6 \pm 11.9$ & $\mathrm{p}=0.7365$ \\
\hline Med (Min-Max) & $68.5(31-89)$ & $67(40-77)$ & $68(31-89)$ & Wilcoxon \\
\hline Sex & & & & \\
\hline Men & 28 & 3 & 31 & $\mathrm{p}=0.2677$ \\
\hline Female & 6 & 2 & 8 & Fisher \\
\hline HBs Ag (+) or HCV & & & & \\
\hline HBs Ag (+) & 6 & 1 & 7 & $\mathrm{p}=1.0000$ \\
\hline $\mathrm{HCV}(+)$ & 23 & 4 & 27 & Fisher \\
\hline Non B-non C & 5 & 0 & 5 & \\
\hline $\mathrm{CH}$ or $\mathrm{LC}$ & & & & \\
\hline $\mathrm{CH}$ & 9 & 1 & 10 & $\mathrm{p}=1.0000$ \\
\hline $\mathrm{LC}$ & 25 & 4 & 29 & Fisher \\
\hline Differentiation of $\mathrm{HC}$ & & & & \\
\hline Poor & 9 & 0 & 9 & $\mathrm{p}=0.0005^{\mathrm{a}}$ \\
\hline Moderate & 21 & 0 & 21 & Mantel-Haenszel \\
\hline Well & 4 & 5 & 9 & \\
\hline Stage & & & & \\
\hline I & 1 & 3 & 4 & $\mathrm{p}=0.0027^{\mathrm{a}}$ \\
\hline II & 6 & 1 & 7 & Mantel-Haenszel \\
\hline III & 8 & 1 & 9 & \\
\hline IV A & 15 & 0 & 15 & \\
\hline IV B & 4 & 0 & 4 & \\
\hline Diameter of tumor & & & & \\
\hline Mean \pm SD & $49.9 \pm 30.0$ & $20.6 \pm 7.3$ & $46.1 \pm 29.3$ & $\mathrm{p}=0.0216^{\mathrm{a}}$ \\
\hline Med (Min-Max) & $40(15-100)$ & $20(11-30)$ & $40(11-100)$ & Wilcoxon \\
\hline Portal thrombus & & & & \\
\hline$(-)$ & 27 & 5 & 32 & $\mathrm{p}=0.5628$ \\
\hline$(+)$ & 7 & 0 & 7 & Fisher \\
\hline $\mathrm{AFP}(\mathrm{ng} / \mathrm{ml})$ & & & & \\
\hline Mean \pm SD & $38656 \pm 154614$ & $38.9 \pm 46.8$ & $33705 \pm 144676$ & $\mathrm{p}=0.1104$ \\
\hline Med (Min-Max) & $203(1-874000)$ & $21(3.5-117)$ & $117(1-874000)$ & Wilcoxon \\
\hline PIVKA-II (mAU/ml & & & & \\
\hline Mean \pm SD & $4995 \pm 17817$ & $21 \pm 11.5$ & $4529 \pm 16997$ & $\mathrm{p}=0.0560$ \\
\hline Med (Min-Max) & 417 (10-95700) & $20(10-33)$ & $356.5(10-95700)$ & Wilcoxon \\
\hline AFP-L3 (\%) & & & & \\
\hline Mean \pm SD & $33.5 \pm 31.0$ & $7.5 \pm 7.1$ & $29.4 \pm 29.9$ & $\mathrm{p}=0.2325$ \\
\hline Med (Min-Max) & $27.5(0-84.9)$ & $6.6(0-16.9)$ & $16.9(0-84.9)$ & Wilcoxon \\
\hline
\end{tabular}

${ }^{a}$ Significantly different between nuclear c-Yes-positive and -negative groups.

years). Of the 39 patients, 27 were positive for hepatitis $C$ virus (HCV)-RNA and 7 were positive for hepatitis B surface antigen (HBs Ag), and the remaining 5 were negative for both (Table I). The histological grade and the stage of HCC were determined according to the criteria of the International Working Party (11) and the International Union against Cancer (12). The fibrotic stage of the liver was evaluated according to the classification by Desmet et al (13). 
Additional tissues were obtained by liver biopsy from 58

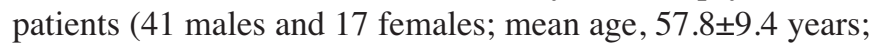
range, 40-76 years) with chronic hepatitis $(\mathrm{CH})$ including cirrhosis. Fifty-three patients with $\mathrm{CH}$ were positive for HCV-RNA and 4 patients were positive for HBs Ag. Fifty-eight $\mathrm{CH}$ cases included 12 at fibrosis stage 1 (F1), 8 at F2, 9 at F3 and 29 at F4. Five normal liver samples were obtained from patients with liver metastases of colon cancer (4 males and 1 female; mean age, 60.2 \pm 4.1 years; range, 56-67 years) during surgery. All serum samples of these patients were negative for both $\mathrm{HCV}$ and $\mathrm{HBs} \mathrm{Ag}$.

Cell culture. HLE, HLF, Hep 3B and PLC/PRF/5 cells, a kind gift of the Health Science Research Resource Bank (Osaka, Japan), were used as human HCC cell lines. The cells were cultured in Dulbecco's modified Eagle's medium (Gibco-BRL, Tokyo, Japan) supplemented with $10 \%$ fetal calf serum (Gibco), $100 \mu \mathrm{g} / \mathrm{ml}$ penicillin and $100 \mu \mathrm{g} / \mathrm{ml}$ streptomycin at $37^{\circ} \mathrm{C}$ under $5 \% \mathrm{CO}_{2}$ in air.

Chemicals and antibodies. Avidin-biotin-peroxidase complex (ABC) kits were purchased from Funakoshi Chemical Co. (Tokyo, Japan). All other chemicals were purchased from Sigma Chemical Co. or Wako Pure Chemical Co. (Tokyo, Japan), unless otherwise mentioned. Two anti-c-Yes monoclonal antibodies used in this study were purchased from Santa Cruz Biotechnology (clone F7; Santa Cruz, CA, USA) and Transduction Laboratories (clone 1; Tokyo, Japan). The optimal dilutions of antibodies used for Western blotting in the present study were as follows: anti-c-Yes antibody (clone 1), 1:1000; anti-horseradish peroxidase (HRP)-anti-mouse IgG, 1:2000. The optimal dilution of anti-c-Yes antibody (clone F7) for immunohistochemistry was 1:500.

Immunohistology for human liver tissues. We prepared $2-\mu \mathrm{m}$ sections from formalin-fixed, paraffin-embedded tissue blocks. Sections of the HCC tissue specimens were immunohistologically stained using the ABC method, as described in our previous study (14-16). Briefly, to detect c-Yes, sections were placed in $10 \mathrm{mM}$ citrate buffer ( $\mathrm{pH} \mathrm{6.0)}$ ) and processed at $500 \mathrm{~W}$ at $95^{\circ} \mathrm{C}$ for $10 \mathrm{~min}$ in a microwave oven. Sections were deparaffinized in xylene, dehydrated in a graded series of alcohol solutions, and then mixed with a solution containing $0.5 \%$ hydrogen peroxide to block endogenous peroxidase activity. After washing with phosphate-buffered saline (PBS), the sections were processed for immunostaining. Primary incubation was performed overnight at $24^{\circ} \mathrm{C}$ with the monoclonal antibody (clone F7) against c-Yes. Immunoreactivity products were visualized using diaminobenzidine, and the sections were counterstained with Mayer's hematoxylin. The specificity of immunostaining was examined using non-immune mouse $\mathrm{IgG}$ as a negative control for primary antibodies.

Immunohistology of HCC cell lines. Immunohistological staining of c-Yes in human HCC cells was performed by means of the $\mathrm{ABC}$ method as described in our previous report (16). Briefly, HCC cells were cultured on tissue culture chamber slides (Nunc, Naperville, IL, USA). The cells were rinsed three times with ice-cold PBS, air-dried at room temperature, fixed with acetone for $1 \mathrm{~min}$ and washed three times with
PBS at room temperature. Endogenous peroxidase was blocked with $3 \%$ hydrogen peroxide in PBS. The cells were washed with PBS, immunostained, and then incubated overnight at $24^{\circ} \mathrm{C}$ with monoclonal antibody (clone 1) against c-Yes. Immunoreactivity products were visualized using diaminobenzidine, and the sections were counterstained with Mayer's hematoxylin.

Gel electrophoresis and Western blotting. Sodium dodecyl sulfate-polyacrylamide gel electrophoreses (SDS-PAGE) was performed following the technique described by Laemmli (17), and Western blotting was performed as described by Towbin et al (18), using the optimal dilution of primary antibodies and HRP-linked secondary antibodies. Immunoreactive proteins were visualized with an enhanced chemiluminescence detection system (Amersham Japan Co., Tokyo, Japan) on a radiograph film. The exposure time for Western blotting was $30 \mathrm{sec}$ at room temperature for all samples.

Preparation of subcellular fractionations from liver tissues and human HCC cells. In order to examine the distribution of c-Yes in the liver tissues and HCC cell lines, we thawed and homogenized the samples with 2 volumes of lysis buffer containing $0.25 \mathrm{M}$ sucrose, $0.1 \mathrm{M} \mathrm{MgCl}_{2}, 10 \mathrm{mM}$ Tris- $\mathrm{HCl}$ at $\mathrm{pH} 7.4,1 \mathrm{mM}$ of each of the protease inhibitors phenylmethylsulphonylfluoride, pepstatin and aprotinin, and $50 \mathrm{mM}$ leupeptin. The homogenate was centrifuged at $8,000 \mathrm{x} \mathrm{g}$ for $30 \mathrm{~min}$ to remove unbroken tissues and nuclei. The supernatant was then centrifuged at $100,000 \mathrm{x}$ g for $60 \mathrm{~min}$ in a Beckman Airfuge to separate the membranous and cytoplasmic fractions. The particulate and supernatant were the membranous fraction and cytoplasmic fraction, respectively. The membranous fraction was washed with a lysis buffer, and then resuspended in a solubilization buffer $(2.3 \%$ SDS, $62.5 \mathrm{mM}$ Tris- $\mathrm{HCl}$ at pH 6.6, $10 \mathrm{mM}$ ethylaminediamine-N, N, N', N'-tetra acid disodium salt tetrahydrate and protease inhibitors). Equivalent amounts of protein from the membranous and cytoplasmic fractions were used for SDS-PAGE and Western blotting.

The extraction of the nuclear protein was performed following the method described in our previous report (19). All steps were carried out at $4^{\circ} \mathrm{C}$. Liver tissue and cell line samples were homogenized in 5 volumes of $50 \mathrm{mM}$ Tris- $\mathrm{HCl}$ (pH 7.4) containing $0.32 \mathrm{M}$ sucrose, $1 \mathrm{mM}$ ethylene glycolbis (B-aminoethyl ether)-N, N, N', N'-tetraacetic acid, $3 \mathrm{mM}$ benzamidine, $0.1 \mu \mathrm{g} / \mathrm{ml}$ soybean trypsin inhibitor, $10 \mu \mathrm{g} / \mathrm{ml}$ leupeptin, $25 \mathrm{mM} \mathrm{KCl}$ and $5 \mathrm{mM} \mathrm{MgCl}_{2}$. The homogenate was centrifuged at $600 \mathrm{x}$ g for $10 \mathrm{~min}$. The pellets were collected and homogenized in 2 volumes of $2.2 \mathrm{M}$ sucrose containing $3.3 \mathrm{mM} \mathrm{CaCl}, 3 \mathrm{mM}$ bezamidine, $0.1 \mu \mathrm{g} / \mathrm{ml}$ soybean trypsin inhibitor, and $10 \mu \mathrm{g} / \mathrm{ml}$ leupeptin. After centrifugation at 4,000 x g for $60 \mathrm{~min}$, the pellet was collected in the same buffer and subjected to SDS-PAGE and Western blot analyses.

Protein assay. The protein concentration was determined according to the Bradford's dye-binding assay (20).

Antibody array to screen proteins binding to nuclear c-Yes. To detect proteins binding to nuclear c-Yes, we used an antibody array (Hypromatrix, Inc., Worcester, MA, USA) in 


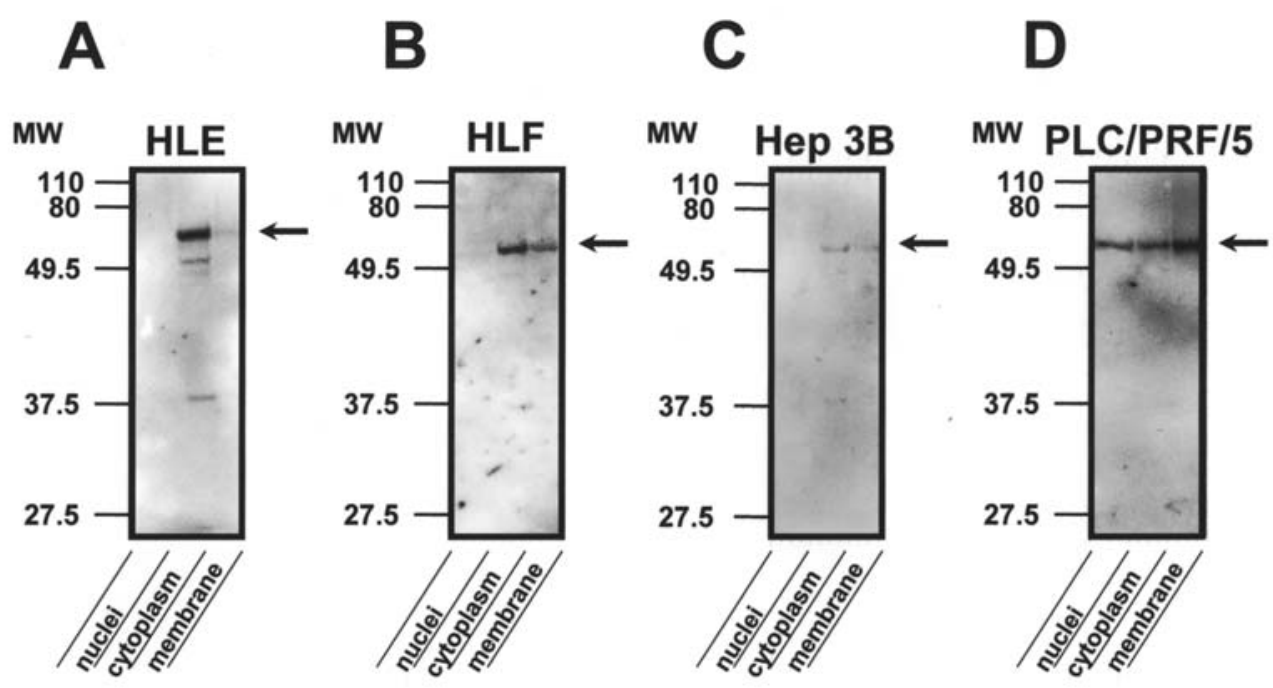

Figure 1. c-Yes expression in the nuclear, cytoplasmic and membranous fractions of various HCC cell lines. A, B, C and D represent Western blot analyses of c-Yes in the HLE, HLF, Hep 3B and PLC/PRF/5 cell lines, respectively. Note that the expression of c-Yes in PLC/PRF/5 cells was detected not only in the cytoplasmic and membranous fractions, but also in the nuclear fraction. Arrows indicate bands corresponding to c-Yes.

which 400 antibodies against signal transduction molecules are immunobilized at each predetermined position on the nitrocellulose membrane. The antibody array membranes were incubated for $1 \mathrm{~h}$ at room temperature with $5 \%$ dry milk in Tris-buffered saline Tween-20 (TBST) consisting of $150 \mathrm{mM}$ $\mathrm{NaCl}, 25 \mathrm{mM}$ Tris-HCl, $0.05 \%$ Tween-20 (pH 7.5), and then incubated with nuclear lysates from nuclear c-Yes positive PLC/PRF/5 and nuclear c-Yes negative Hep 3B cells for $2 \mathrm{~h}$. After incubation, the membranes were washed with TBST three times for 10 min each time and incubated for $2 \mathrm{~h}$ with HRP-conjugated anti-c-Yes monoclonal antibody. Interactive proteins for nuclear c-Yes in PLC/PRF/5 cells were visualized using diaminobenzidine as the color substrate.

Statistical analysis. Data are expressed as means \pm SD. The significance of differences between observations was determined according to the Wilcoxon, Fisher and MantelHaenszel tests. Statistical significance was set at $p<0.05$.

\section{Results}

Western blotting of c-Yes in nuclear, cytoplasmic and membranous fractions of the HCC cell lines, HLE, HLF, Hep $3 B$ and $P L C / P R F / 5$. The expression of c-Yes in HLE (Fig. 1A), HLF (Fig. 1B) and Hep 3B (Fig. 1C) cells was detected in cytoplasmic and membranous fractions, but was not found in nuclear fractions (Fig. 1, arrows); it was detected in the cytoplasmic, membranous and nuclear fractions in the PLC/PRF/5 cell line (Fig. 1D).

Immunohistochemistry of c-Yes in the HCC cell lines, HLE, $H L F, H e p 3 B$ and PLC/PRF/5. The expression of c-Yes in HLE (Fig. 2A), HLF (Fig. 2B) and Hep 3B (Fig. 2C) cells was localized in both the cytoplasm (Fig. 2A-C, arrows) and membranes (Fig. 2A-C, arrowheads), while its expression in PLC/PRF/5 cells was also identified in the nuclei (Fig. 2D, arrows) as well as in the cytoplasm and membrane. The localization of c-Yes in HLE, HLF, Hep 3B and PLC/PRF/5 cells based on immunohistochemical analysis was consistent with the results obtained by Western blotting (Fig. 1).

Immunohistochemistry of c-Yes in human normal, $\mathrm{CH}$ and cirrhotic livers. Immunohistological studies of c-Yes showed no staining in hepatocytes of normal (Fig. 3A) or CH (Fig. 3B) liver samples. In contrast, c-Yes expression in cirrhotic livers was detected in the cytoplasm and membranes of hepatocytes along the limiting plates and at the periphery of regenerating nodules (Fig. 3C, arrow). However, the expression of c-Yes was not detected in the nuclei of hepatocytes in cirrhotic livers. No nuclear c-Yes expression was detected in any normal, $\mathrm{CH}$ or cirrhotic liver samples analyzed in the present study.

c-Yes expression in malignant liver tissues. Immunohistological examinations showed that the expression of c-Yes in human HCC was divided into two staining patterns: the cytoplasmic and nuclear staining patterns. As shown in Fig. 4A, HCC with cytoplasmic c-Yes staining pattern had weak c-Yes expression in the membranes of some cancer cells (arrow heads), but did not have nuclear c-Yes expression. As shown in Fig. 4B, HCC with nuclear c-Yes staining pattern had weak $\mathrm{c}-$ Yes expression in the membranes and cytoplasm of cancer cells. In total, the cytoplasmic staining pattern was detected in $34(87 \%)$ of $39 \mathrm{HCC}$ cases and the nuclear staining pattern was detected in the remaining $5(13 \%)$ cases.

Western blotting of c-Yes in the membranous, cytoplasmic and nuclear fractions of human HCC tissues. Fig. 5 shows the Western blotting results of HCC samples corresponding to Fig. 4, respectively. In HCC tissues without nuclear c-Yes expression, c-Yes expression was detected in the membranous and cytoplasmic fractions, but not in the nuclear fraction (Fig. 5A), while in those with nuclear c-Yes expression, it was found in the nuclear fraction of cancer cells as well as in the membranous and cytoplasmic fractions (Fig. 5B). These data are consistent with the immunohistochemical results (Fig. 4). 


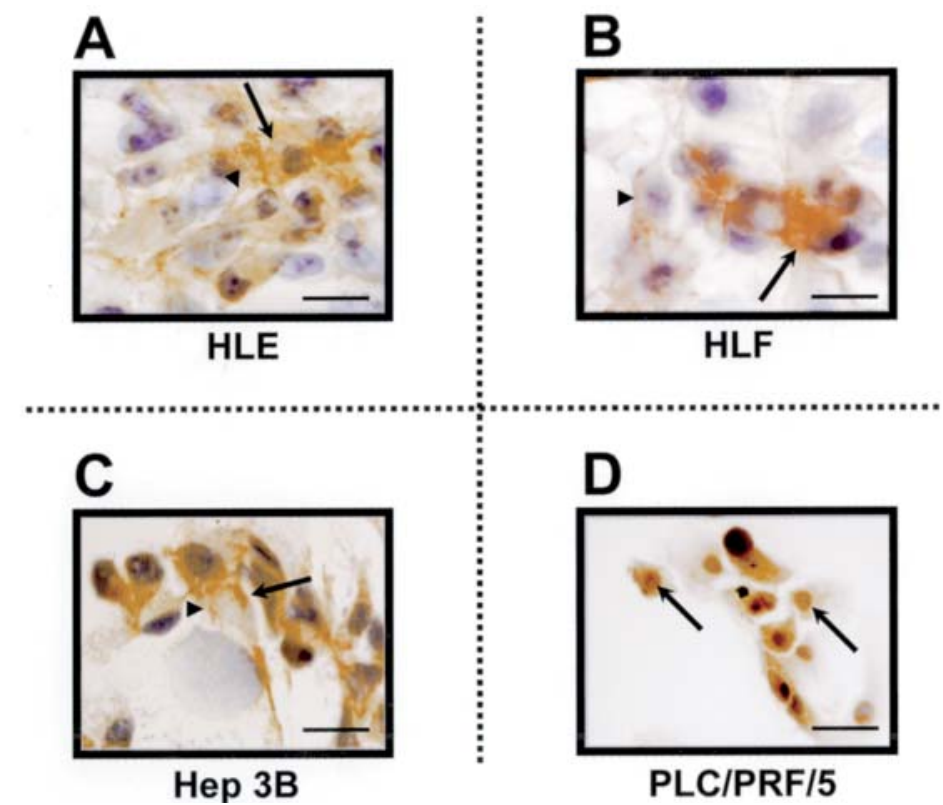

Figure 2. Immunohistological localization of c-Yes in HCC cell lines. A, B, C and D represent immunohistochemical analyses of c-Yes in the HLE, HLF, Hep 3B and PLC/PRF/5 cell lines, respectively. The expression of c-Yes in HLE, HLF and Hep 3B cells was localized in both the cytoplasm (A-C, arrows) and membranes (A-C, arrow heads), while its expression in PLC/PRF/5 cells was also detected in the nuclei (D, arrows) as well as in the cytoplasm and membranes. All cell lines were counterstained with Mayer's hematoxylin. Bars, $20 \mu \mathrm{m}$.

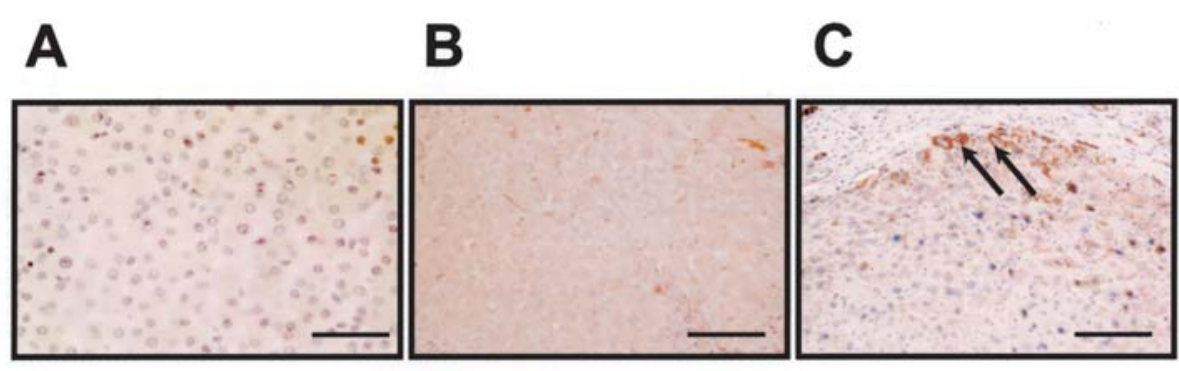

Figure 3. Immunohistochemistry of c-Yes in normal, $\mathrm{CH}$ and cirrhotic livers. A-C show sections reacting with a c-Yes antibody in normal, $\mathrm{CH}$ and cirrhotic samples, respectively. No c-Yes expression was detected in normal (A) or CH (B) samples, however, in the cirrhotic samples (C) it was immuno-stained in some hepatocytes along the limiting plates and at the periphery of the regenerating nodules (arrows). Note that no expression of c-Yes was detected in the hepatocellular nuclei of normal, $\mathrm{CH}$ or cirrhotic samples. All sections were counterstained with Mayer's hematoxylin. Bars, $50 \mu \mathrm{m}$.
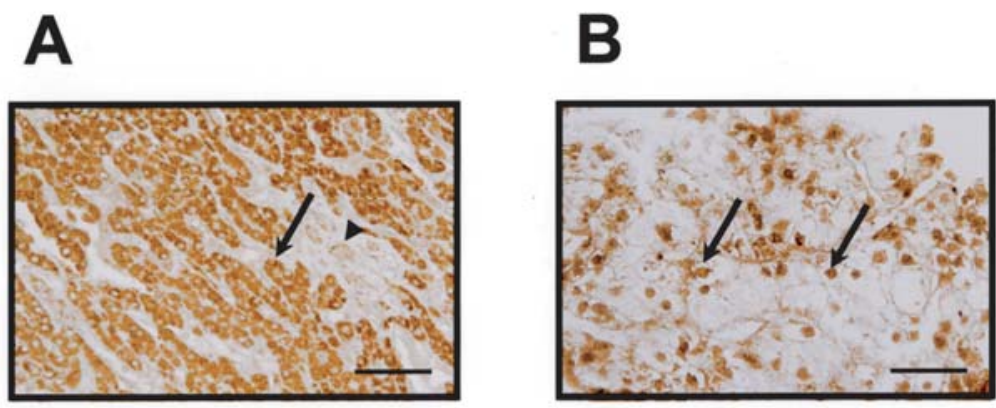

Figure 4. Immunohistochemistry of c-Yes in human HCC. A and B show moderate and well-differentiated clear cell HCC, respectively. (A) Shows the cytoplasmic (arrow), membranous staining pattern (arrow head) of c-Yes, while (B) shows the nuclear staining pattern (arrows) as well. In the present study, HCC without nuclear c-Yes was detected in $34(87 \%)$ of 39 cases, and HCC with nuclear c-Yes was identified in the remaining $5(13 \%)$. All sections were counterstained with Mayer's hematoxylin. Bars, $50 \mu \mathrm{m}$.

Relationship between HCC with nuclear c-Yes and clinical parameters. As shown in Table I, HCC with nuclear c-Yes expression was detected in $5(13 \%)$ of 39 HCC cases. HCC cases with nuclear c-Yes expression were detected at a 


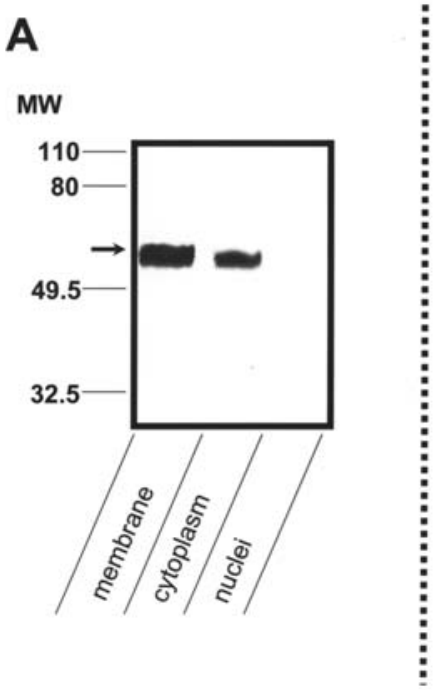

B

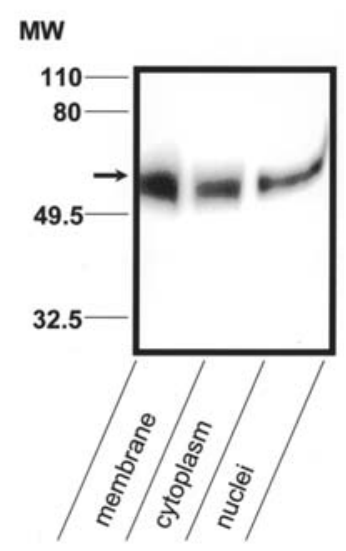

Figure 5. Western blotting of c-Yes in the membranous, cytoplasmic and nuclear fractions of human HCC. (A) and (B) correspond to (A) and (B) in Fig. 4, respectively. As shown in (A), c-Yes expression (arrow) was detected in the membranous and cytoplasmic fractions, but not in the nuclear fraction of HCC. On the other hand, (B) shows that c-Yes expression (arrow) was found not only in the membranous and cytoplasmic fractions, but also in the nuclear fraction of HCC.
A

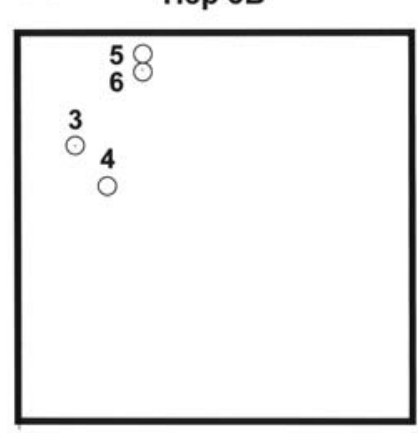

B

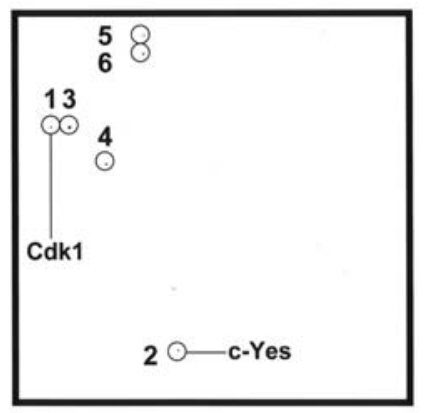

Figure 6. Comprehensive analysis using a protein antibody array to screen proteins binding to nuclear c-Yes. Representative result of the protein antibody array in Hep 3B cells without nuclear c-Yes expression is shown in (A). Representative result of the protein antibody array in PLC/PRF/5 cells with nuclear c-Yes expression is shown in (B). Spots 3-6 are non-specific. Spot 1 was identified as Cdk1, and Spot 2 as c-Yes.

significant rate in well-differentiated, small tumors at early stage HCC. There were no significant differences in the relationships between nuclear c-Yes expression and sex, age, hepatitis viral infection, background liver tissues, portal thrombus or tumor markers.

Detection of nuclear c-Yes-interacting proteins. In order to identify nuclear c-Yes-interacting proteins in PLC/PRF/5, we used a protein antibody array. This examination demonstrated the binding of nuclear c-Yes to Cdk1 (Fig. 6B, spot 1). As shown in Fig. 6, because spots 3-6 in PLC/PRF/5 were also detected in Hep 3B without nuclear c-Yes expression, they were regarded as non-specific spots. Spot 2 was identified as c-Yes.

\section{Discussion}

Src-family tyrosine kinases are proto-oncogene products and non-receptor type tyrosine kinases that bind to the cellular membrane; their subcellular distribution is membranous and/or cytoplasmic. In the present study, we found the nuclear expression of c-Yes in a subset of human HCC tissues and in a human HCC cell line. In addition, all HCCs with nuclear c-Yes expression were well-differentiated, small tumors at the early stages. To the best of our knowledge, the present report is the first study showing the identification of nuclear c-Yes in cancer cells and discussing the relationship between nuclear c-Yes expression and the clinicopathological data of HCC.

Among Src-family tyrosine kinases, subcellular localization of c-Lyn has been detected in the nuclei as well as in membranes and cytoplasm in HL-60 myeloid leukemia (21) and HeLa cells (22). Moreover, another Src-family kinase, $\mathrm{c}-\mathrm{Src}$, has been shown to be localized in the nuclei of calciuminduced differentiating keratinocytes (23). However, prior to the present study, no subcellular localization of c-Yes had been examined in various liver diseases, including HCC. It was shown in the present study that nuclear c-Yes expression was not detected in hepatocytes of normal, $\mathrm{CH}$ or cirrhotic livers but was detected clearly in a subset of HCC tissues. Furthermore, all HCCs with nuclear c-Yes expression were well-differentiated, small tumors at the early stages, suggesting that nuclear c-Yes may play a role in the early stages of hepatocarcinogenesis. Furthermore, nuclear c-Yes expression could be a useful marker to detect early-stage HCC.

Although the present study demonstrated the presence of nuclear c-Yes in cancer cells in a subset of HCC samples, the mechanism for the existence of nuclear c-Yes in the cancer cells remains unclear. c-Yes is known to play an essential role in the signal transduction pathways involved in the regulation of cell differentiation (24-27). Therefore, to investigate its role in differentiation in $\mathrm{HCC}$, we analyzed the relationship between the expression of nuclear c-Yes and the histopathological grade of HCC. Our results demonstrated that all cases with nuclear c-Yes expression were well-differentiated HCC, suggesting that the expression of nuclear c-Yes may play an important role in maintaining differentiation and in preventing the appearance of less differentiated HCC.

In the present study, we found evidence that nuclear c-Yes binds to $\mathrm{Cdk} 1$, however, the function of this phenomenon remains unclear. The binding of another Src-family tyrosine kinase, nuclear c-Lyn, to Cdk1 has also been reported $(21,22)$, supporting the present data. It is possible that the association of c-Yes with Cdk1 in the nuclei may contribute to malignant transformation in a subset of HCC cases.

In conclusion, c-Yes expression in the nuclei of cancer cells was found at the early stages of hepatocarcinogenesis and well-differentiated HCC, suggesting that such nucleuslocated c-Yes could be a useful marker in detecting early stage HCC. Additionally, HCC may be a novel model for studying the function of nuclear c-Yes in malignant transformation. The suppression of nuclear c-Yes may offer a novel strategy in prohibiting the development of HCC. Further studies are necessary to investigate such possibilities. 


\section{Acknowledgements}

This work was supported in part by Grants-in-Aid for Scientific Research (C-17590649) from the Ministry of Education, Culture, Sports, Science and Technology of Japan, and by the Alumni Association of the Faculty of Medicine of Kagawa University.

\section{References}

1. Courtneidge SA: Activation of the $p p 60^{c-s r c}$ kinase by middle T antigen binding or by dephosphorylation. EMBO J 4: 1471-1477, 1985.

2. Piwnica-Worms H, Saunders KB, Roberts TM, Smith AE and Cheng SH: Tyrosine phosphorylation regulates the biochemical and biological properties of pp60 ${ }^{\text {c-src }}$. Cell 49: 75-82, 1987.

3. Cartwright CA, Eckhart W, Simon S and Kaplan PL: Cell transformation by pp $60^{\mathrm{c}-\mathrm{src}}$ mutated in the carboxy-terminal regulatory domain. Cell 49: 83-91, 1987.

4. Bolen JB: Non-receptor tyrosine protein kinases. Oncogene 8: 2025-2031, 1993.

5. Park J, Meisler AI and Cartwright CA: c-Yes tyrosine kinase activity in human colon carcinoma. Oncogene 8: 2627-2635, 1993.

6. Hirsch CL, Smith-Windsor EL and Bonham K: Src family kinase members have a common response to histone deacetylase inhibitors in human colon cancer cells. Int J Cancer 118: 547-554, 2006.

7. Loganzo F Jr, Dosik JS, Zhao Y, Vidal MJ, Nanus DM, Sudol M and Albino AP: Elevated expression of protein tyrosine kinase c-Yes, but not c-Src, in human malignant melanoma. Oncogene 8: 2637-2644, 1993.

8. Marchetti D, Parikh N, Sudol M and Gallick GE: Stimulation of the protein tyrosine kinase c-Yes but not c-Src by neurotrophins in human brain-metastatic melanoma cells. Oncogene 16: 3253-3260, 1998.

9. Feng H, Masaki T, Nonomura T, Morishita A, Jian G, Nakai S, Deguchi A, Uchida N, Himoto T, Iwama H, Usuki $H$, Wakabayashi $\mathrm{H}$, Izuishi $\mathrm{K}$, Yoshiji $\mathrm{H}$, Kurokohchi $\mathrm{K}$ and Kuriyama S: Activation of c-Yes in hepatocellular carcinoma: a preliminary study. World J Gastroenterol (In press).

10. Han NM, Curley SA and Gallick GE: Differential activation of pp60 $60^{\text {-src }}$ and pp62 $62^{\text {c-yes }}$ in human colorectal carcinoma liver metastases. Clin Cancer Res 2: 1397-1404, 1996.

11. International Working Party: Terminology of nodular hepatocellular lesions. Hepatology 22: 983-993, 1995.

12. International Union Against Cancer (UICC): TNM Classification of Malignant Tumors. 5th edition. Sobin LH and Wittekind $\mathrm{Ch}$ (eds). Wiley-Liss, New York, pp74-77, 1977.

13. Desmet VJ, Gerber M, Hoofnagle JH, Manns M and Scheuer PJ: Classification of chronic hepatitis: diagnosis, grading and staging. Hepatology 19: 1513-1520, 1994.
14. Yoshida S, Masaki T, Feng H, Yuji J, Miyauchi Y, Funaki T, Yoshiji H, Matsumoto K, Uchida N, Watanabe S, Kurokohchi K and Kuriyama S: Enhanced expression of adaptor molecule p46 Shc in nuclei of hepatocellular carcinoma cells: study of LEC rats. Int J Oncol 25: 1089-1096, 2004.

15. Masaki T, Tokuda M, Yoshida S, Nakai S, Morishita A, Uchida N, Funaki T, Kita Y, Funakoshi F, Nonomura T, Himoto T, Deguchi A, Kimura Y, Izuishi K, Wakabayashi H, Usuki H, Yoshiji H, Watanabe S, Kurokohchi K and Kuriyama S: Comparison study of the expressions of myristoylated alanine-rich $\mathrm{C}$ kinase substrate in hepatocellular carcinoma, liver cirrhosis, chronic hepatitis and normal liver. Int J Oncol 26: 661-671, 2005.

16. Yukimasa S, Masaki T, Yoshida S, Uchida N, Watanabe S, Usuki H, Yoshiji H, Maeta T, Ebara K, Nakatsu T, Kurokohchi K and Kuriyama S: Enhanced expression of p46 Shc in the nucleus and p52 Shc in the cytoplasm of human gastric cancer. Int J Oncol 26: 905-911, 2005.

17. Laemmli UK: Cleavage of structural proteins during the assembly of the head of bacteriophage T4. Nature 227: 680-685, 1970.

18. Towbin H, Staehelin T and Gordon J: Electrophoretic transfer of proteins from polyacrylamide gels to nitrocellulose sheets: procedure and some applications. Proc Natl Acad Sci USA 76: 4350-4354, 1979

19. Masaki T, Tokuda M, Shiratori Y, Shirai M, Matsumoto K, Nishioka $\mathrm{M}$ and Omata $\mathrm{M}$ : A possible novel src-related tyrosine kinase in cancer cells of LEC rats that develop hepatocellular carcinoma. J Hepatol 32: 92-99, 2000.

20. Bradford MM: A rapid and sensitive method for the quantitation of microgram quantities of protein utilizing the principle of protein-dye binding. Anal Biochem 72: 248-254, 1976.

21. Kharbanda S, Saleem A, Yuan ZM, Kraeft S, Weichselbaum R, Chen LB and Kufe D: Nuclear signaling induced by ionizing radiation involves colocalization of the activated p56/p53 lyn tyrosine kinase with p34 ${ }^{\text {cdc2 }}$. Cancer Res 56: 3617-3621, 1996.

22. Radha V, Nambirajan S and Swarup G: Association of Lyn tyrosine kinase with the nuclear matrix and cell-cycle-dependent changes in matrix-associated tyrosine kinase activity. Eur J Biochem 236: 352-359, 1996.

23. Zhao Y, Sudol M, Hanafusa H and Krueger J: Increased tyrosine kinase activity of c-Src during calcium-induced keratinocyte differentiation. Proc Natl Acad Sci USA 89: 8298-8302, 1992.

24. Kamei T, Hamlin GP, Chapman BM, Burkhardt AL, Bolen JB and Soares MJ: Signaling pathways controlling trophoblast cell differentiation: Src family protein tyrosine kinases in the rat. Biol Reprod 57: 1302-1311, 1997.

25. Zhao $Y$, Uyttendaele $H$, Krueger JG, Sudol M and Hanafusa $H$ Inactivation of c-Yes tyrosine kinase by elevation of intracellular calcium levels. Mol Cell Biol 12: 7507-7514, 1993.

26. Park J, Meisler AI and Cartwright CA: c-Yes tyrosine kinase activity in human colon carcinoma. Oncogene 8: 2627-2635, 1993.

27. Krueger J, Zhao YH, Murphy D and Sudol M: Differential expression of p62 c-yes in normal, hyperplastic and neoplastic human epidermis. Oncogene 6: 933-940, 1991. 